\title{
The Effects of the Effective Use of the New Information and Communication Technology in the Classroom
}

\author{
Prof. Assoc. Dr. Daniela Tamo \\ Department of the English Language, Faculty of Foreign Languages, \\ Tirana University \\ Email: danielatamo@gmail.com
}

\section{Doi:10.5901/jesr.2014.v4n2p298}

\begin{abstract}
In the last decades there have been steps forward in the use of Information and Communication Technologies (ICT) in the classroom. The teachers have changed their traditional way of teaching and the students their traditional way of learning. The teachers and students are pleased with the new information and communication technologies because they see a number of advantages that help them a lot in the teaching and learning process. The students are using the technology as a tool or support for communicating with their teachers and among them. Hence they are in an active role rather than in passive role of the recipient of information transmitted by the teacher, textbook. The students make choices how to generate or obtain and display information. On the other hand, the teacher plays the role of the facilitator, provides guidelines, suggestions, etc. Furthermore, the students and teachers are aware of the fact that these new forms of the teaching and learning process present some disadvantages that should be well taken into consideration. Thus, this paper presents the many advantages and some disadvantages of ICT in explaining the new material, the new methods developed in order to satisfy the growing needs of the students in search of more knowledge.
\end{abstract}

Keywords: active role, facilitator, increased motivation, information and communication technology, self-esteem, teaching and learning process.

\section{Introduction}

This article attempts to explore the problem of introducing ICT into EFL lessons. A large number of educational institutions in many parts of the world have exclusively begun introducing the integration of computer technology into teaching. The diversity of learning programs continue to shift and change according to the demands of society. Nevertheless, since the development of communicative skills, language learning requires social interaction between the teacher and the students and among the students themselves, the use of computers has for a long time been regarded only as a support tool with regard to certain skill areas (Brandal, 2005). Information, Communication and Technology (ICT) could be a complement to conventional teaching of English among students who learn English as a foreign language. English and ICT have become essential skills for a vast amount of non-native English speakers to ensure full participation in the information society, (Jung, 2006) which is directly related to the wide spread of English and ever growing technological advancements today. Internet and modern technology has brought the world together wherever the students are. Previously there was some doubt regarding the technology in the classroom assuming that technology was replacing teachers. But technology - ICT is not a replacement for teachers and if it is used properly, it can be very affective and effective in the EFL classroom. Students and teachers perceive that both English and computers are tools in the learning and teaching process.

\section{What is ICT and How Can it be Used in Teaching English as a Foreign Language?}

ICT stands for Information, Communication and Technology, which emerged in the 1980's. The acronym ICT which is the combination of both terms Information and Communication, were put together in order to emphasize the merging of both technologies. This phrase is also used to describe a range of technologies in order to gather, store, retrieve, process, analyze and transmit information (Internet Advisory Board, 2008). ICT use in general terms is any use of "computing devices such as desktop computers, laptops, handheld computers, software, or Internet in schools for instructional purposes" (Hew \& Brush, 2007, p. 225). Thus it refers to the use of technology by teachers for instructional preparation, 
instructional delivery, and to the use of technology as a learning tool for students (Inan \& Lowther, 2010).

ICT is a tremendous aid in the classroom. Teachers all around the world are using ICT and bringing languages and culture into the classroom. ICT is just as much or even more a communicative language.

Many researches are conducted as to the effects of innovative technological tools in the EFL teaching and learning process. The general finding supports the fact that technology has the capacity to afford opportunities for powerful teaching and learning environments (Hermans, Tondeur, van Braak, \& Valcke, 2008) and can impact students' learning (Cancannon, Flynn, \& Campbell, 2005), motivation (Mahdizadeh, Biemans, \& Mulder, 2008), critical thinking (Lim, Teo, Wong, Khine, Chai, \& Divaharan, 2003), and autonomy (Claudia, Steil, \& Todesco, 2004). Many research studies have also been conducted in relation to the factors that affect ICT use by teachers in different school levels. These research studies point out that the use of ICT is not an easy process at the beginning. It is a complex and slow process and there are many important factors that play a key role. Such factors as the characteristics of teachers and students, level of technology use, and pedagogical philosophies of the country's educational system are among the most important ones.

An analysis of the history of Computer-Assisted Language Learning (CALL) shows that ICT tools have been actively and widely used in language classes from the initiation of computers into the world due to the fact that language teachers have always been the pioneer of using innovative teaching tools in their classes (Amiri, 2000). The history of CALL consists of three distinct phases, i.e., behavioristic, cognitive, and interactive CALL, each of which is characterized with both a certain level of computer technology including mainframes, PCs, and multimedia technologies and a specific language learning and teaching approach (Warschauer, 1996). Although the phases are all distinct and separate in their own way, they all rely on each other in order to function. The Behaviorist CALL was based mainly on behaviorist theory of learning that is a type of language learning consisting of repetitive drilling and practicing. The computer acted as a tutor that delivered the language instruction. In the 1970's and 1980's was the second phase, Communicative CALL. Many language theorists believed that the drill and practice programs did not allow for authentic communication. The last phase can be described as Integrative CALL: Multimedia. This phase unlike the others is based not on theory but on multimedia computers and the internet. Multimedia can be defined a simultaneous, combined use of several media at the same time such as films, slides, flashing lights and music (Stein, 1982). The internet can be defined as a computer network consisting of a worldwide network of computer networks that use the TCP/IP network protocols to facilitate data transmission and exchange (Freedman, 1999). There is also hypermedia, which makes the internet and multimedia even more powerful in that multimedia sources are linked together (Stein, 1982). Overall, the history of CALL shows that computers can serve a variety of uses in regards to language teaching. It can be a tutor where everything that is heard has to be repeated, practice drills in order to help the students perfect the language, as well as a starting point for discussions or a tool for writing and research. The value of ICTs must be assessed according to the degree to which it promotes the attainment of the objectives of the specific subject. EFL teachers have utilized ICT tools for teaching and learning purposes.

\section{The Effects of ICT use for Teachers}

\section{A. Advantages of ICT use for teachers}

The teachers can play a crucial role in relation to the quality of students' learning, and they are the ones that decide what actually takes place in the individual classroom. The use of technology in teaching such as World Wide Website, multimedia presentation tools and so forth can offer a number of benefits. There is no doubt that the role of the teacher is of paramount importance in the process of integrating ICT into the classroom. ICT provides a variety of different approaches as well as learning styles that reinforce the material delivered in other formats. These are useful tools helping the teachers in using different interactive techniques.

In a blended learning environment that uses ICT tools, it is easier for the language teacher to use different approaches with students and accommodate different learning styles and the different needs of fast or slow language learners.

ICT allows teachers to organize their teaching in an efficient manner. With technology, teachers can visualize the abstract concept and create the real world simulations. ICTs not only help students understand the topic better, but they can save the teachers' time for explaining the abstract matters to students.

Technology provides teachers with a wide range of resources that are useful for their teaching. If they have limited time for developing the teaching materials, they can directly go to the website and select any materials or topics that meet their needs. Usually, the already available resources can offer more than what is needed by teachers. 
Technology can also help teachers develop networks with other teachers from different parts of the world who share similar interests or who have the expertise in certain field. They can help teachers discuss with their colleagues, solve their teaching problems and, therefore, enhance their professionalism.

EFL teachers use ICT tools for preparing teaching materials and activities to be used in teaching pronunciation (Lee, 2008), grammar (Al- Jarf, 2005), vocabulary (Tsou, Wang, \& Li, 2002), listening and speaking (Hochart, 1998), communication skills (Lee, 2002), reading (Akyel \& Ercetin, 2009), and writing (Chikamatsu, 2003).

Learning applications prepared by teachers or commercially produced ones such as drills, tutorials, and computerbased tasks are used in the classroom to promote collaborative learning of English skills (Beatty \& Nunan, 2004).

EFL teachers use computer-mediated-communication (CMC) or software as a tool for making authentic and meaningful communication. Therefore technology can provide learners with a range of authentic materials and tasks that have a positive influence on their autonomy.

Another benefit of the use of ICT is the opportunity that ICT-based tools give to language teachers so that they can tutor their learners more effectively. With the help of ICT tools and the constantly growing number of available educational resources language teachers are able to give individual and personalized guidance to the learners.

B. The obstacles of the teachers

Teachers experience the obstacles to successful integration of ICTs in their teaching on a daily basis. Many teachers are afraid of using ICT tools due to different reasons. It has been suggested that the development of teachers' positive attitudes toward ICT can be a key player in reducing teachers' resistance to computer use that is associated with computer anxiety.

Some teachers think that the class will be noisy. The students will not be focused on their task, but will take every opportunity to start browsing the Web at will, find some sites, and play games, playing around and wasting time, etc. But students will be students. Some wish to obtain the new knowledge, others will always try to play truant. The teachers have to accept the situation and have to do their best. But if students are trained and understand that ICT is a tool, a source of knowledge, they will listen to the teacher and follow the steps suggested by him. Time limit is a concern for the teachers. It is time-consuming to produce such materials and keep them up to date so that the pupils have new challenges and can progress into exercises constantly offering revision of new vocabulary, grammar and other topics.

The teachers are afraid of the new technology. Probably the language teachers are not so good at it and have the fear of showing the lack of knowledge in front of their students. They are anxious of not having the appropriate skills about computer, computer ownership, and frequency of computer use (Baloglu \& Cevik, 2008). It is assumed that computer anxiety can be a barrier to basic computer skills and teachers with higher levels of computer anxiety might experience difficulties in using computer in their classes and thus would avoid that. Despite a strong desire of teachers to use ICT in their classes, sometimes they cannot use it to increase the quality of teaching and learning due to lack of essential ICT skills.

The absence of adequate help or technical support to facilitate teachers' technology mediated teaching is another factor which may hinder teachers' teaching. Different researchers have revealed that many teachers, when having some difficulties with the technology equipment being used, had to give up using it because there was no one available to help deal with the problems. The lack of technical staff was considered by teachers as one of the main obstacles in their successful use of technology based pedagogy.

Teachers' age and teaching experience is another barrier found by the researches. ICT use decreases with age and teaching experience of teachers and those younger teachers incorporate ICT tools into their teaching more than their older counterparts (Inan \& Lowther, 2010). It is evident in the literature that teachers' age and experience are related to their lack of computer knowledge and skills in terms of computer-based or computer-managed instruction and lack of enough training to exploit effective ways of integrating instructional technology into language teaching. Previous research (e.g., Pamuk \& Peker, 2009) shows that teachers who are above middle age and who did not have much formal computer training in their high school or college education are more likely to exhibit computer anxiety than younger teachers and this can be reflected in their limited use of ICT use in the classroom.

Another fear of the teachers is related to the logistic aspect, to the operation and functioning of the technology. They know that sometimes the internet crashes. In such a case, the language teacher has to be prepared to continue the process doing other exercises, or using other techniques to manage the class.

The integration of ICT into the regular school curriculum is another obstacle. The teachers know that there is quite a rigid plan, a curriculum they have to follow, as well as a strict school timetable. All the teachers have to deal with the same problems: how to include and integrate ICT, search for information, new types of lessons, international projects and 
other types of cooperation-communication, into their usual work so that they don't harm the educational process.

\section{The Advantages of ICT use for Students}

ICTs are valuable since they seem ideal for promoting the student centered teaching and learning through the access they provide to sources of information and arenas for interaction. Language classrooms are increasingly turning into blended learning environments that focus on active learning. Active learning advances the learning process and thus raises the quality of the language learning experience. Jonassen et al. (1999) define technology-enhanced meaningful learning as active, authentic and cooperative. In the last decade, changing conceptions of learning and rapid technological advances have been accompanied by changes in language teaching and learning. Blended language learning uses multiple teaching and guiding methods by combining face-to-face sessions with online activities and utilizing a mix of technology-based materials. The growing use of ICT in blended language learning environments has changed the face of language teaching and learning in a beneficial way and will continue to do so along with future technological innovations.

The use of several media-audio, video, authentic contexts and real-world experiences help language learners with different learning styles to assimilate the content according to their needs. The ICTs are used in compliance with the students' level of competence, skills and tasks.

ICT-and the Internet in particular-provides language learners with the opportunity to use the language that they are learning in meaningful ways in authentic contexts. The Internet provides an easy and fast access to the use of current and authentic materials in the language being studied, which is motivating for the language learner. Such authentic materials include online newspapers, webcasts, podcasts, newsroom video clips or even video sharing websites such as YouTube, etc. Language teachers can ask learners to access the information online, thus helping them learn with current and real-time materials.

Another motivating language learning opportunity using ICT is provided by chat rooms and virtual environments where the language learner can practice not only the written use of the language, but also practice speaking and pronunciation, without the fear of making mistakes.

Another advantage is the increase of motivation. The students having shown less initiative in carrying out the assignments, have shown more motivation when they are asked to conduct their duties using different forms of ICT. Some teachers think that students' motivation is increased as a result of student satisfaction with the immediate feedback provided by the computer and the sense of accomplishment and power gained in working with technology.

ICT experience must be pleasant, rewarding, important and without coercion. It's a more facilitating atmosphere in the classroom. The students can more easily comment, commenting on each other's work, offer assistance, and discuss what they are doing. Students feel relaxed in their classes, they do not feel the stress because technology provides different ways in which students can demonstrate what they understand, for example by programming a simulation to demonstrate a concept rather than trying to explain it verbally. Enjoyment is a part of effective learning, thereby raising the learners' interest, increasing personal discovery, generating enthusiasm and the desire to learn, as a result promoting an interest to improve the learners' motivation. Students love working with ICTs and especially using ICTs as instruments to aid in the development of their language skills. Researches have shown that tasks that involve variety and diversity are more likely to facilitate an interest in learning. Students are likely to accept the use of ICTs if they find them useful and easy to use.

Studies done on the use of ICTS claim that pupils using them are motivated to stay on task longer and that they take pride in their achievements using the materials. Researchers have found out that students using them are more dedicated and committed to the tasks compared to the students in classes that don't use ICTs.

Enhancement of student self-esteem is reported a very good advantage. Both the increased competence they feel after mastering technology-based tasks and their awareness of the value placed upon technology within their culture, lead to increases in students' sense of self-worth. The teachers see more confidence in the students and it's not just computers, it's a multitude of things, but they can do things on the computers that most of their parents can't do and that's very empowering and exciting for them. Students clearly take pride in being able to use the same computer-based tools employed by professionals. Students gain a sense of empowerment from learning to control the computer and to use it in ways they associate with the real world.

Students are able to handle more complex assignments and do more with higher-order skills because of the supports and capabilities provided by technology.

Another effect of technology cited by a great majority of teachers is the opportunities it affords to students for 
cooperation and collaboration among them. Language teachers are introducing ICT-enhanced language learning projects, including simulations, between their students and groups in other countries, thus widening the language learning perspective into that of learning about the cultural context of the language being used. Previously, students or classes would write letters or later even e-mails to each other. Today, using ICT they can skype or chat online, where they can not only write to each other in real-time, but also see each other and speak to each other online. Students are thus able to write, read, speak, listen, and react to a conversation using ICT as part of the language learning process. They are motivated to communicate and collaborate with peers to produce common products. These beneficial ICTenhanced language learning activities call for the teacher to organize and monitor them, although in a blended language learning class the overall role of the teacher has changed from the traditional authoritative role to that of a facilitator.

Peer tutoring is another benefit. When the students work together in pairs or small groups using technology on different projects, they are inclined to cooperate together, help each other and tutor each other. This is done for many reasons. One very important reason is that the group can be successful only if all group members are doing their respective work. So they help each other a lot at the computer.

Improvement of language skills and increase of communicative skills are achieved through the ICT use. These skills are related to handling information and the language through which it is conveyed in the stages of searching, analyzing and processing information (Lanni, 2005). When ICT use is accompanied with other skills students benefit and gain much more than what was expected. Jarvis (1998) believes that by integrating basic IT skills in the EFL classroom, the students are developing language skills and are equipped with technology skills as well.

On-line debate is an excellent medium for generating social construction of knowledge. According to Elia (2007) "ICT ... plays apart in fostering intercultural competence", which is a part of learning a second or foreign language.

Talented pupils are provided with a new environment that challenges their knowledge and less talented ones are given the chance to "catch up" by repeating exercises which they did not manage on their first attempt, perhaps at home.

ICT use improves learning English along with convenience and efficiency. The use of ICT may lead to: a greater interest and involvement in learning; greater self-esteem; determination to achieve specific tasks; spending more time on the learning task; trying to do better than one's peers; and achieving more control over one's own learning.

\section{Conclusions}

In the technological revolution and the information age, using technology in teaching English becomes "a fact of life" (Chapelle, 2001, p. 1, in Jung, 2006) and becomes a part of the broader reality of life at the $21^{\text {st }}$ century.

ICT helps to improve the teaching and learning process for students learning a foreign language. The types of technologies can improve teaching and learning by increasing teacher and student efficiency and reaching different learning styles.

The success of ICT when implemented in the foreign language classroom depends on the teacher and the students. It is very important that the teacher is well versed in using the tools surrounding ICT in order to fully take advantage of the benefits that ICT offers compared to a conventional classroom. The need for teacher intervention is essential to avoid leaving the technology to control the lessons. The teacher needs to see the real effect ICT materials have on the learning process. Furthermore, there should be an appropriate balance between hands-on and other work and the motivational aspects of using ICT will be effective only with appropriate planning and guidance from the teacher.

ICT has enormous potential to improve learners' achievement by expanding students' learning experience, increasing motivation, enhancing enjoyment and interest, facilitating collaboration, fostering learner autonomy, enhancing self-esteem, increasing commitment to the learning task, promoting global understanding, developing language skills if it is used effectively in the context where learning takes place. Students have events under their personal control and are given the opportunity to do tasks that involve variety and diversity.

Any successful implementation of new technology in education requires the development of the teachers and students positive attitudes toward it.

\section{References}

Akyel, A. and Ercetin, G. (2009). Hypermedia reading strategies employed by advanced Learners of English. System, 37(1), 136-52. http://dx.doi.org/10.1016/j.system.2008.05.002

Albirini, A. (2006). Teachers' attitudes toward information and communication technologies: The case of Syrian EFL teachers. Computers \& Education, 47(4), 373-398. http://dx.doi.org/10.1016/j.compedu.2004.10.013

Alghazo, I. M. (2006). Quality of Internet use by teachers in United Arab Emirates. Education, 126(4), 769-781. 
Al-Jarf, R. S. (2005). The effects of online grammar instruction on low proficiency EFL college students' achievement. The Asian EFL Journal Quarterly, 7(4), 166-90.

Al-Oteawi, S. M. (2002). The perceptions of administrators and teachers in utilizing information technology in instruction, administrative work, technology planning and staff development in Saudi Arabia. Doctoral dissertation, Ohio University.

Amiri, F. (2000). IT-literacy for language teachers: Should it include computer programming? System, 28(1), 77-84. http://dx.doi.org/10.1016/S0346-251X(99)00061-5

Aqui, Y. M. (2005). Characteristics of the online learner: Experiences, participation level, and achievement.

Baloglu, M., and Cevik, V. (2008). Multivariate effects of gender, ownership, and the frequency of use on computer anxiety among high school students. Computers in Human Behavior, 24(6), 2639-2648. http://dx.doi.org/10.1016/j.chb.2008.03.003

Baloglu, M., and Cevik, V. (2009). A multivariate comparison of computer anxiety levels between candidate and tenured school principals. Computers in Human Behavior, 25(5), 1102-1107.

Carol A. Chapelle. Language Learning \& Technology, Vol. 2, No. 1, July 1998, pp. 22-34.

Chu, J. L. (2000). Assessment of the integration of technology into the curriculum by middle and high school teachers. Dissertation Abstract International, 61(8).

Granger, C.A., Morbey, M.L., Lotherington, H., Ooston, R. D., \& Wideman, H. H. (2002). Factors contributing to teachers successful implementation of IT. Journal of Computer Assisted Learning, 18(1), 480-488.

J. S. Dougald (2009). The use of information and communication technology (ICT) in the EFL classroom as a tool to promote L2 (English) among non-native pre-service English teachers. A thesis for Masters Degree.

Lund, A. (2004). The teacher as interface: Teachers of EFL in ICT-rich environments: Beliefs, practices, appropriation. Oslo: UniPub.

Mueller, J., Wood, E., Willoughby, T., Ross, C., \& Specht, J. (2008). Identifying discriminating variables between teachers who fully integrate computers and teachers with limited integration. Science Direct. Computers and Education, 51(4), 1523-1537

Rahimi, M. \& Yadollahi, S. (2011). ICT Use in EFL Classes: A Focus on EFL Teachers' Characteristics. World Journal of English language, Vol. 1, N0.2, October 2011.

Warschauer, M. (1996). Computer assisted language learning: an introduction. Available from http://www.gse.uci.edu/markw/call.html

Warschauer, M. \& Whittaker P. F. (1997, October). The internet for English teaching: Guidelines for teachers. The internet TESL journal, Vol. III, No. 10, October 1997. Available from http://iteslj.org/Articles/Warschauer-Internet.html 